\title{
Cumulative doses of radioiodine in the treatment of differentiated thyroid carcinoma: knowing when to stop
}

\author{
Doses cumulativas de iodo radioativo no tratamento do \\ carcinoma diferenciado de tireoide: sabendo a hora de parar
}

Raul Martins-Filho', Laura S. Ward'2, Barbara J. Amorim',

Allan O. Santos', Mariana C. L. de Lima', Celso D. Ramos', Patricia S. Matos', Lígia V. M. Assumpção', Edwaldo E. Camargo', Elba C. S. C. Ełchebehere'

\begin{abstract}
Objective: Evaluate the efficacy of cumulative doses (CDs) of ${ }^{131}$-iodide therapy (RIT) in differentiated thyroid cancer (DTC). Subjects and methods: The probability of progressive disease according to CDs was evaluated in patients $\leq 45$ years old and $>45$ years old and correlated to tumor-node-metastasis (TNM), thyroglobulin values, histological types and variants, age, and zduration of the disease. Results: At the end of a follow-up period of $69 \pm 56$ months, 85 out of 150 DTC patients submitted to fixed doses RIT had no evidence of disease, 47 had stable disease and 18 had progressive disease. Higher CDs were used in the more aggressive variants $(p<0.0001)$, higherTNM stages $(p<0.0001)$, and follicular carcinomas $(p=0.0034)$. Probability of disease progression was higher with $\mathrm{CDs} \geq 600 \mathrm{mCi}$ in patients $>45$ years old and with CDs $\geq 800 \mathrm{mCi}$ in patients $\leq 45$ years. Conclusion: Although some patients may still respond to high CDs, the impact of further RIT should be carefully evaluated and other treatment strategies may be warranted. Arq Bras Endocrinol Metab. 2010;54(9):807-12
\end{abstract}

\section{Keywords}

Cumulative dose; radioiodine therapy; ${ }^{131}$-iodide; differentiated thyroid cancer

\section{RESUMO}

Objetivo: Avaliar a eficácia de doses cumulativas (DCs) da terapia com iodeto- ${ }^{131}$ I (RIT) no câncer diferenciado de tiroide (CDT). Sujeitos e métodos: A probabilidade de doença em progressão conforme a DC foi calculada em pacientes com idade $\leq 45$ e $>45$ anos e correlacionada com o TNM, valores de tiroglobulina sérica, tipos histológicos e variantes, idade e tempo de doença. Resultados: Ao final de um seguimento de $69 \pm 56$ meses, 85 dos 150 pacientes CDT submetidos a doses fixas de RIT não tinham evidência de doença, 47 tinham doença estável e 18 , doença progressiva. DCs mais elevadas foram usadas nas variantes agressivas $(p<0,0001)$, maior estágio TNM ( $p<0,0001)$ e nos carcinomas foliculares $(p=0,0034)$. A probabilidade de doença em progressão foi maior com $\mathrm{DCs} \geq 600 \mathrm{mCi}$ em pacientes $>45$ anos e com $\mathrm{DCs} \geq 800$ $\mathrm{mCi}$ em pacientes $\leq 45$ anos. Conclusão: Apesar de alguns pacientes ainda responderem a altas DCs, o impacto de RITs deve ser cuidadosamente avaliado e outras estratégias terapêuticas devem ser consideradas. Arq Bras Endocrinol Metab. 2010;54(9):807-12

Descritores

Dose cumulativa; radioiodoterapia; iodeto- ${ }^{-131}$; carcinoma diferenciado de tiroide
'Division of Nuclear Medicine, Faculdade de Ciências Médicas, Universidade Estadual de Campinas (FCM/Unicamp), São Paulo, SP, Brazil ${ }^{2}$ Laboratory of Cancer Molecular Genetics, FCM/Unicamp, São Paulo, SP, Brazil ${ }^{3}$ Department of Pathology, FCM/ Unicamp, São Paulo, SP, Brazil ${ }^{4}$ Division of Endocrinology, FCM/ Unicamp, São Paulo, SP, Brazil

Correspondence to: Elba C. S. C. Etchebehere Serviço de Medicina Nuclear, Hospital de Clínicas, Unicamp Av. Zeferino Vaz, $s / n$ Caixa postal 6142 13081-970 - Campinas, SP, Brazil elba@mn-d.com

Received on May/17/2010 Accepted on Nov/3/2010

\section{INTRODUCTION}

$\mathrm{D}$ ifferentiated thyroid cancer incidence has been rising all over the world and recent data demonstrate that rates have also increased for large and aggressive tumors diagnosed with distant metastasis (SEER stage) (1-3). Standard treatment for DTC patients includes total or near-total thyroidectomy followed by adjuvant radioiodine therapy (RIT) to destroy remnant, benign 
or malignant thyroid tissue (4-6). Two methods are widely available: the so-called fixed empirical method currently used by most medical services, and the dosimetric method. There is still no evidence of a clear advantage of one method over the other for the calculation of the administered dose (7).

The majority of patients with DTC have a good prognosis and high cure rates (8.9). However, the disease persists or recurs with a considerable impact on quality of life in up to $60 \%$ of the patients $(8,9)$. Depending on the course of the disease additional treatments using radioiodine may become necessary. As long as metastases and recurrences are radioiodine-avid, it is the most effective treatment option and high response rates are achievable (10). Unfortunately, approximately $15 \%$ of these patients do not respond to RIT (8-11). Improved survival is associated with responsiveness to RIT (12).

There is no pre-established timing in the literature of when to stop RIT. Limits to $1,000 \mathrm{mCi}$ have been suggested; however, they are empirical and do not consider all variables such as stage, tumor histology, age, tumor marker levels, clinical course, side effects and quality of life during RIT $(5-7,12,13)$. Thus, many patients are submitted to cumulative doses of up to $2 \mathrm{Ci}$, however, the actual benefit of this is questionable.

The aim of this study was to evaluate the efficacy of RIT in DTC regarding cumulative doses and its relationship with the clinical course, primary tumor histology, stage, age and serum thyroglobulin ( $\mathrm{Tg}$ ) levels.

\section{MATERIAL AND METHODS}

\section{Patients}

This retrospective case-control study was approved by the Research Ethics Committee of the Faculty of Medical Sciences - Universidade Estadual de Campinas (FCM-Unicamp). We analyzed the records of 232 DTC patients who were submitted to RIT with ${ }^{131} \mathrm{I}$ -iodide. After excluding patients with incomplete data, 150 patients were selected for the study (125 women; mean age of $44.3 \pm 14.6$ years).

All patients were managed according to a standard protocol which included total thyroidectomy. Patients with preoperatively or intraoperatively palpable neck node metastases underwent regional neck dissection. At the time of the initial treatment, surgical specimen was analyzed and classified according to the WHO classification, and patients were classified according to the sixth edition of the The American Joint Committee on Cancer (AJCC)/ International Union Against Cancer (UICC) TNM (14).

\section{Radioiodine therapy (RIT)}

RITs were performed with fixed doses, as follows: $3,700 \mathrm{MBq}(100 \mathrm{mCi})$ for thyroid remnants, 5,550 $\mathrm{MBq}(150 \mathrm{mCi})$ for lymph node metastases, 7,400 $\mathrm{MBq}(200 \mathrm{mCi})$ for pulmonary metastases, 11,100 $\mathrm{MBq}(300 \mathrm{mCi})$ for bone metastases.

In patients who required second or third RIT the decision on the new dose was based on the location of the metastases, on the dose previously administered, on persistently elevated $\mathrm{Tg}$ levels (with or without positive WBI), and to some extent on tumor volume, normally adding $925 \mathrm{MBq}$ to $1,850 \mathrm{MBq}(25-50 \mathrm{mCi})$ to the new dose. For example, a patient with thyroid remnants after total thyroidectomy without lymph node metastases would initially receive $3,700 \mathrm{MBq}(100 \mathrm{mCi})$ of ${ }^{131} \mathrm{I}$ -iodide. If this patient presented with persistent thyroid remnants on follow-up scans, without lymph node metastases, another RIT would be performed with 4,625 - 5,550 MBq (125-150 mCi) of ${ }^{131}$ I-iodide. However, if this same patient required a new treatment due to the appearance of bone metastasis in follow-up, RIT would be performed with $11,100 \mathrm{MBq}(300 \mathrm{mCi})$.

Lymph node metastases were diagnosed after total thyroidectomy with cervical neck dissection or during follow-up.

\section{Follow-up}

Patient follow-up ranged from 19 to 383 months (mean $69 \pm 56$ months, median 49.15 months). According to a routine protocol, follow-up included periodic total body scans, serum TSH and Tg measurements, as well as other eventual procedures to detect distant metastasis, including cervical ultrasound, chest CT, whole body iodide scan (WBI), whole body ${ }^{99 \mathrm{~m}} \mathrm{Tc}$ - sestamibi scan (after the year 1992), ${ }^{18}$ F-FDG PET/CT (after the year 2007), and biopsy. Stimulated Tg levels were obtained when whole body scans (WBS) were performed. A first serum $\mathrm{Tg}$ result $(\mathrm{Tgl})$ was obtained before patients underwent the first RIT, the second $\operatorname{Tg}(\mathrm{Tg} 2)$ was obtained after a second RIT (when indicated), and the same criterion was considered for the third $(\operatorname{Tg} 3)$, fourth ( $\mathrm{Tg} 4)$ and ensuing $\mathrm{Tg}$ measurements. Using these parameters disease status was classified as: no evidence of disease (NED), stable disease (SD) and progressive disease (PD). This classification was established 
when the maximum tolerated dose for each patient was determined. There was no variation of this classification during the study.

NED was established as: undetectable $\mathrm{Tg}$ levels (with or without levothyroxine suppression), two consecutive WBI scans without local-regional uptake or distant metastases; other imaging studies (cervical ultrasounds, chest CTs, whole body ${ }^{99 \mathrm{~m}} \mathrm{Tc}$-sestamibi scans, ${ }^{18} \mathrm{~F}-\mathrm{FDG}$ PET/CT scans) without evidence of disease; suppressed serum Tg level $<2.0 \mathrm{ng} / \mathrm{mL}$ and stimulated serum Tg level $<10.0 \mathrm{ng} / \mathrm{mL}$.

SD was established as: unaltered Tg levels, persistent cervical uptake and/or metastases in annual WBI, suppressed serum Tg level $>2.0 \mathrm{ng} / \mathrm{mL}$ or serum $\mathrm{Tg}$ level $>10.0 \mathrm{ng} / \mathrm{mL}$ but without progressive elevation and no new metastatic foci.

PD was established as: increasing serum $\mathrm{Tg}$ levels despite RIT and/or new metastatic foci detected by imaging studies. Patients with PD were treated surgically whenever possible whether the metastases were loco-regional or distant. This approach was performed in order to improve the efficacy of RIT (15).

Table 1 summarizes median Tg levels and RIT doses administered to patients after the corresponding evaluation.

Table 1. Serum median Tg levels 1 to 4 and median ${ }^{131} \mid$-iodide therapy (RIT) corresponding administered doses 1 to 4

\begin{tabular}{lcc}
\hline Patient data & Number of patients & Median \\
\hline Tg1 $(\mathrm{ng} / \mathrm{mL})$ & 150 & 3.35 \\
Dose 1 & & 101.50 \\
$\mathrm{Tg}$ 2 $(\mathrm{ng} / \mathrm{mL})$ & 64 & 4.10 \\
Dose 2 & & 200.00 \\
$\mathrm{Tg}$ 3 $(\mathrm{ng} / \mathrm{mL})$ & 30 & 25.50 \\
Dose 3 & & 250.00 \\
Tg4 (ng/mL) & 11 & 36.90 \\
Dose 4 & & 330.00 \\
Tg/ stimulated TSH & 150 & 0.69 \\
Cumulative dose (mCi) & 150 & 150.00 \\
\hline
\end{tabular}

Seven patients with PD had non-avid radioiodine metastasis and one patient died after 8 years of DTC diagnosis, due to a second primary tumor. This patient had received a $\mathrm{CD}$ of $300 \mathrm{mCi}$.

\section{Statistical analysis}

The chi-squared test or the Fisher's exact test was performed in order to verify associations or compare proportions. The Mann-Whitney test was applied to compare continuous variables between two groups. For three or more variables among groups, the Kruskal-
-Wallis test followed by the Tukey's test was used to locate these differences. Spearman's linear coefficient was applied to verify the relationship among continuous variables. A multiple logistic regression analysis adjusting age and follow-up time was used to identify factors associated with the evidence of disease. In order to calculate the estimated probability of disease status (NED, SD or PD), we created a model that took into account the age (above or below 45 years) and the cumulative dose. The significance level applied was $5 \%$.

\section{RESULTS}

Papillary carcinomas (PC) were found in 125 cases and follicular carcinomas (FC) in the remaining 25 cases. An experienced pathologist (PSM) classified the tumors as "classic DTC" (116 cases) or as having an "aggressive histology"; the latter included 34 patients $(22.7 \%)$ presenting Hürthle cell, invasive FC, tall cell variant, diffuse sclerosis variant or columnar cell variant of PC. Eighty-five cases $(56.7 \%)$ were considered a TNM stage I, 28 were stage II (18.7\%); 14 stage III (9.3\%), and 23 stage IV (15.3\%). Table 2 summarizes the patient data.

Eighty-five out of the 150 patients $(56.7 \%)$ were classified as NED; 47 patients had SD (31.3\%), and the remaining 18 patients had $\mathrm{PD}(12.0 \%)$.

Table 2. Clinical and pathological features at diagnosis of 150 patients with differentiated thyroid carcinomas followed-up from 19 to 383 months after ${ }^{131}$-iodide therapy (RIT)

\begin{tabular}{lcc}
\hline & $\begin{array}{c}\text { Cumulative } \\
\text { frequency }\end{array}$ & Percentage \\
\hline Sex & 125 & 83.3 \\
Female & 25 & 16.7 \\
Male & & \\
Histology & 125 & 83.3 \\
$\quad$ Papillary carcinomas & 25 & 16.7 \\
Follicular carcinomas & & \\
Variant & 116 & 77.3 \\
Classical & 34 & 22.7 \\
Aggressive & 6 & $17.7^{\star}$ \\
$\quad$ Invasive follicular carcinoma & 10 & $29.4^{*}$ \\
$\quad$ Hurtle & 12 & $35.3^{*}$ \\
$\quad$ Tall cell & 3 & $8.8^{*}$ \\
$\quad$ Diffuse sclerosis & 3 & $8.8^{*}$ \\
$\quad$ Columnar cells & & \\
TNM stage & 85 & 56.7 \\
I & 28 & 18.7 \\
II & 14 & 9.3 \\
III & 23 & 15.3 \\
IV
\end{tabular}

* Percentages relative to the group of 34 cases of aggressive differentiated thyroid carcinomas. 
$\mathrm{Tg} 1$ levels ranged from 0 to $6,000 \mathrm{ng} / \mathrm{mL}$; $\mathrm{Tg} 2$ levels were obtained in 71 patients and ranged from 0.2 $\mathrm{ng} / \mathrm{mL}$ to $6,000 \mathrm{ng} / \mathrm{mL}$; Tg3 levels were obtained in 31 patients and ranged from $0.2 \mathrm{ng} / \mathrm{mL}$ to $3,000 \mathrm{ng} /$ $\mathrm{mL}$, and $\mathrm{Tg} 4$ levels were obtained in 11 patients and also ranged from $0.2 \mathrm{ng} / \mathrm{mL}$ to $3,000 \mathrm{ng} / \mathrm{mL}$.

Among the 49 patients with $\mathrm{Tgl}$ levels above $10 \mathrm{ng} /$ $\mathrm{mL}$ that evolved with NED, in 7 patients this occurred after the first RIT dose while 42 patients required more treatment sessions. Thus, RIT was completely effective in treating thyroid remnants in $14 \%$ of the cases and was effective treating the actual disease in $86 \%$ of the patients.

After the first RIT, 79 patients were deemed with SD or NED. Hence, the RIT was effective and no new treatment was necessary for these cases. Tg levels ranged from 0 to $86 \mathrm{ng} / \mathrm{mL}$ in this group. The remaining 71 patients required a second RIT. After the second RIT, 40 patients were considered with SD or NED and their $\mathrm{Tg}$ levels ranged from 0 to $516 \mathrm{ng} / \mathrm{mL}$. The remaining 31 patients required a third RIT. After the third RIT, 20 patients were classified as presenting SD or NED and their Tg levels ranged from 0 to $170 \mathrm{ng} /$ $\mathrm{mL}$. The remaining 11 patients required a fourth RIT.

A striking response was seen in a few patients with high serum $\mathrm{Tg}$ levels. Six out of the 150 patients had $\mathrm{Tgl}$ levels above $500 \mathrm{ng} / \mathrm{mL}$. All 6 patients presented with pulmonary metastases although in 2 of them the WBI scans were negative. The only patient with $\mathrm{Tgl}$ above $6,000 \mathrm{ng} / \mathrm{mL}$ had bone and pulmonary metastases. Among the 6 patients that had serum Tgl levels $>500$ $\mathrm{ng} / \mathrm{mL}$ after a second RIT, two patients responded to RIT treatment and 4 patients maintained $\mathrm{Tg} 2$ levels above $700 \mathrm{ng} / \mathrm{mL}$ and pulmonary metastases. Among these 4 patients with serum $\operatorname{Tg} 2$ levels $>700 \mathrm{ng} / \mathrm{mL}$ one patient responded to RIT and the remaining 3 maintained serum $\mathrm{Tg}$ levels above $500 \mathrm{ng} / \mathrm{mL}$ (two with pulmonary metastases and one with a mediastinal lymph node).

Table 3 summarizes the positive associations confirmed by a multiple logistic regression analysis that showed the disease status was associated with the TNM stage and age on the occasion of diagnosis, with the initial stimulated serum $\mathrm{Tg}$ levels and with the cumulative dose.

Higher cumulative doses were used in the more aggressive histologic variants $(\mathrm{p}<0.0001)$, higher TNM stage tumors $(\mathrm{p}<0.0001)$, and follicular carcinomas $(\mathrm{p}=0.0034)$, while no association was observed with gender $(\mathrm{p}=0.1469)$. Patients with aggressive histologic variants received almost twice the dose $(464 \pm 318$ $\mathrm{mCi})$ of the non-aggressive variants $(240 \pm 192 \mathrm{mCi}$; $\mathrm{p}<0.0001)$. The highest cumulative dose given in this group was $1,100 \mathrm{mCi}$.

The statistic model was created in order to estimate the probability of disease status ( $\mathrm{RD}, \mathrm{SD}$ or $\mathrm{PD}$ ) according to the cumulative dose in patients above and below 45 years of age and is displayed in figures 1 and 2 .

Table 3. Multiple logistic regression analysis of disease status and variables studied

\begin{tabular}{lllll}
\hline Variables & $\begin{array}{c}\text { Disease } \\
\text { status }\end{array}$ & p-value & OR & $\mathbf{9 5 \%} \mathbf{~ c l}$ \\
\hline TNM stage & SD vs. NED & 0.0063 & 4.203 & $1.499 ; 11.783$ \\
& PD vs. NED & 0.0016 & 9.126 & $2.310 ; 36.053$ \\
Age & SD vs. NED & 0.0331 & 0.970 & $0.943 ; 0.998$ \\
& PD vs. NED & 0.6024 & 1.013 & $0.966 ; 1.062$ \\
Cumulative dose & SD vs. NED & $<0.0001$ & 1.005 & $1.003 ; 1.008$ \\
& PD vs. NED & $<0.0001$ & 1.010 & $1.006 ; 1.014$ \\
Stimulated & SD vs. NED & 0.0007 & 1.413 & $1.157 ; 1.727$ \\
Tg levels & PD vs. NED & 0.0005 & 1.430 & $1.170 ; 1.747$ \\
\hline
\end{tabular}

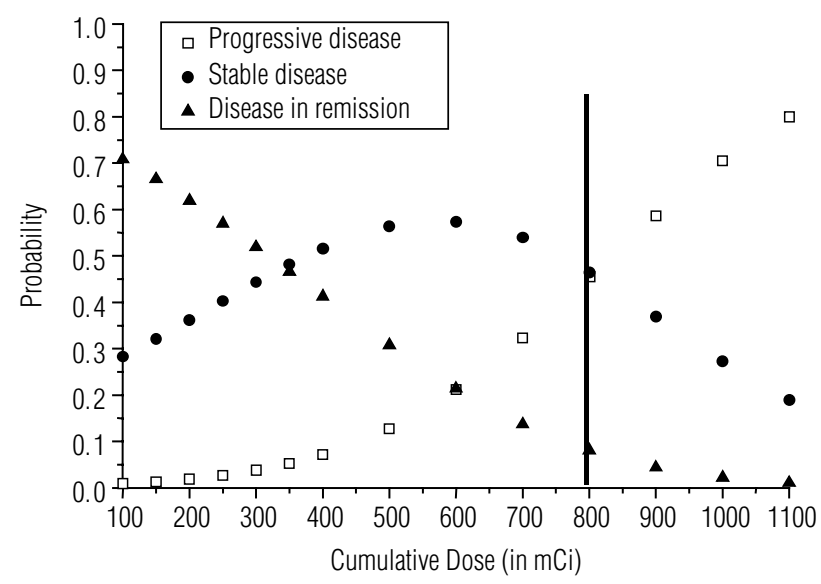

Figure 1. Probability of disease status according to the cumulative doses of RIT for patients $\leq 45$ years of age.

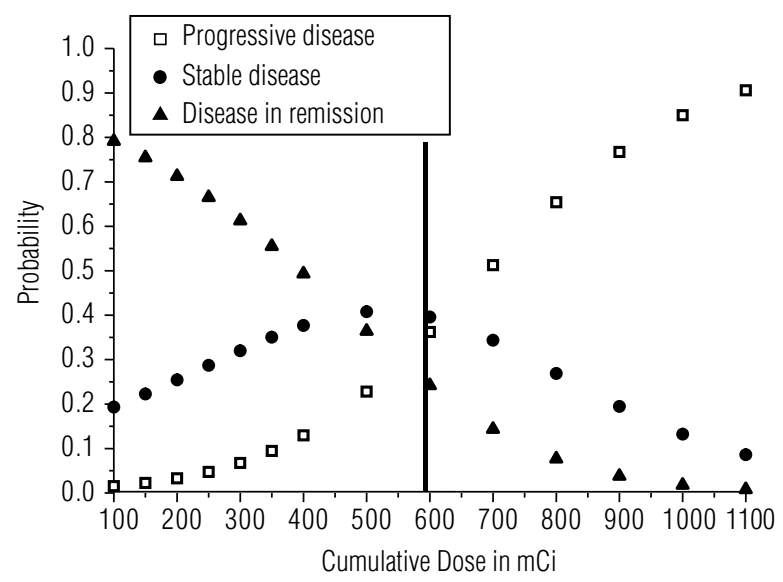

Figure 2. Probability of disease status according to cumulative doses of RIT for patients above 45 years of age. 


\section{DISCUSSION}

There are many studies discussing clinical, pathological and molecular factors related to the prognosis of DTC. However, only a few authors have focused on the impact of the cumulative dose of RIT. The relatively long follow-up period in the present study (up to 32 years) has made it possible to evaluate tumor behavior compared to RIT cumulative doses and their effect on survival. As expected, patients with higher serum Tg levels during the course of the disease had progressive disease and therefore required higher and more frequent therapeutic ${ }^{131}$ I-iodide doses. Also, in accordance to others, we observed that patients with Hürthle cell, invasive FC, tall cell, diffuse sclerosis variant, columnar cells had the worst prognosis (16). These variants have high vascularity and therefore have a higher risk of hematogenic spread. They also frequently present metastases at diagnosis (16), which explains why these patients had $\mathrm{PD}$ and therefore significant higher cumulative doses of RIT. The association between cumulative dose and TNM stage was also expected considering that the higher stages (III and IV) have a worse prognosis $(17,18)$. However, there are conflicting reports in the literature regarding the influence of the histological type (PC vs. FC) on DTC prognosis (19). Mazzaferri and cols. reported similar progression rates when distant metastases were excluded at diagnosis, with FC and PC similar mortality rates $(10 \%$ vs. $6 \%, \mathrm{p}=\mathrm{N} / \mathrm{S})(20)$.

Patients with higher staging (III and IV), above 45 years of age, and aggressive variants have a worse prognosis, greater chances of local recurrence and distant metastases, and require higher and more RIT doses. Consequently, higher cumulative doses are seen in this subgroup of patients as the endpoint is prolonging overall survival. In order to estimate the probability of the possible outcome of these patients, a probability model was created. The estimated probability model was designed to evaluate the relationship between cumulative dose and disease status and thus determine a specific cumulative dose for which the probability of disease progression would be high despite the RIT dose. With our patient population, based on this model, we may suppose that a patient below the age of 45 years has approximately $70 \%$ chance of complete remission of the disease with a cumulative dose of only $100 \mathrm{mCi}$ while the same patient, if requiring cumulative doses in the 1 Ci range may still have a $27 \%$ chance of stabilizing the disease.
We observed that there is a high probability of disease progression with cumulative doses of $600 \mathrm{mCi}$ in patients above 45 years of age, although a few individuals do respond to cumulative doses above $1,000 \mathrm{mCi}$. The disease will only continue to progress in younger patients ( $\leq 45$ years) with higher cumulative doses $(800$ $\mathrm{mCi}$ or higher), despite the fact that some patients may still respond to cumulative doses above $1,000 \mathrm{mCi}$.

A recent study of 77 DTC patients with distant metastases followed-up for a median of 6.1 years reported similar data concluding that age had significantly greater influence on survival than iodine avidity $(21,22)$.

The evaluation of $\mathrm{Tg}$ levels throughout this long period of time is challenging and some variability existed since new techniques with less false negative results have emerged throughout the years. Reference values were determined according to the period in which they were analyzed and in patients in whom these values were discrepant with history and imaging studies, new analyses were performed. Treatment strategies were always based on discussion with a multidisciplinary team to minimize possible discrepancies (23).

Unfortunately, we were not able to evaluate the impact on overall survival $v s$. cumulative dose since the mean follow-up time was below 10 years. A longer follow-up time with a larger number of patients is necessary in order to evaluate the impact of this information on patient management.

In conclusion, although there is no actual cutoff point indicating when RIT should not be considered for therapy, these data indicate caution in patients above 45 years old receiving cumulative doses higher than $600 \mathrm{mCi}$, as well as in younger patients who have already received cumulative doses above $800 \mathrm{mCi}$. Although some patients may still respond to cumulative doses above these levels, we should carefully evaluate the impact of further RIT on their quality of life considering the disease progression rate in between treatments and the availability of other measures, including surgical excision of metastasis, ethanol ablation, chemo-embolization or the emerging targeted molecular therapies.

Disclosure: no potential conflict of interest relevant to this article was reported.

\section{REFERENCES}

1. Enewold L, Zhu K, Ron E, Marrogi AJ, Stojadinovic A, Peoples $\mathrm{GE}$, et al. Rising thyroid cancer incidence in the United States by demographic and tumor characteristics, 1980-2005. Cancer Epidemiol Biomarkers Prev. 2009;18(3):784-91. 
2. Chen AY, Jemal A, Ward EM. Increasing incidence of differentiated thyroid cancer in the United States, 1988-2005. Cancer. 2009;115(16):3801-7.

3. Cordioli MI, Canalli MH, Coral MH. Increase incidence of thyroid cancer in Florianopolis, Brazil: comparative study of diagnosed cases in 2000 and 2005. Arq Bras Endocrinol Metabol. 2009;53(4):453-60.

4. American Thyroid Association (ATA) Guidelines Taskforce on Thyroid Nodules and Differentiated Thyroid Cancer, Cooper DS, Doherty GM, Haugen BR, Kloos RT, Lee SL, Mandel SJ, Mazzaferri EL, Mclver B, Pacini F, Schlumberger M, Sherman SI, Steward DL, Tuttle RM. Revised American Thyroid Association management guidelines for patients with thyroid nodules and differentiated thyroid cancer. Thyroid. 2009;19(11):1167-214.

5. Pitoia F, Ward L, Wohllk N, Friguglietti C, Tomimori E, Gauna A, et al. Recommendations of the Latin American Thyroid Society on diagnosis and management of differentiated thyroid cancer. Arq Bras Endocrinol Metabol. 2009;53(7):884-7.

6. Reiners C, Dietlein M, Luster M. Radio-iodine therapy in differentiated thyroid cancer: indications and procedures. Best Pract Res Clin Endocrinol Metab. 2008;22(6):989-1007.

7. De Klerk JM, Oyen WJ. The continuous debate in literature about the usage of iodine-131 dosing for the ablation of thyroid remnants and metastases. Minerva Endocrinol. 2009;34(1):57-69.

8. Mazzaferri EL, Kloos RT. Clinical review 128: Current approaches to primary therapy for papillary and follicular thyroid cancer. J Clin Endocrinol Metab. 2001;86(4):1447-63.

9. Lin JD, ChaoTC, Hsueh C, Kuo SF. High recurrent rate of multicentric papillary thyroid carcinoma. Ann Surg Oncol. 2009;16(9):2609-16.

10. Ronga G, Filesi M, Montesano T, Di Nicola AD, Pace C, Travascio $L$, et al. Lung metastases from differentiated thyroid carcinoma. A 40 years' experience. O J Nucl Med Mol Imaging. 2004;48(1):12-9.

11. Sipos JA, Kloos RT. lodine-refractory differentiated thyroid cancer: an ominous diagnosis with the potential for a brighter future. Clin Adv Hematol Oncol. 2008;6(10):767-9.

12. Sampson E, Brierley JD, Le LW, Rotstein L,Tsang RW. Clinical management and outcome of papillary and follicular (differentiated) thyroid cancer presenting with distant metastasis at diagnosis. Cancer. 2007;110(7):1451-6.

13. Sawka AM, Brierley JD, Tsang RW, Thabane L, Rotstein L, Gafni A, et al. An updated systematic review and commentary examining the effectiveness of radioactive iodine remnant ablation in well-differentiated thyroid cancer. Endocrinol Metab Clin North Am. 2008;37(2):457-80.

14. Sawka AM, Goldstein DP, Brierley JD, Tsang RW, Rotstein L, Ezzat S, et al. The impact of thyroid cancer and post-surgical radioactive iodine treatment on the lives of thyroid cancer survivors: a qualitative study. PLoS One. 2009;4(1):e4191.

15. Greene FL, Page D, Morrow M, Balch C, Haller D, Fritz A, et al, eds. AJCC Cancer Staging Manual 6th ed. NewYork: Springer; 2002.

16. Sciuto R, Romano L, Rea S, Marandino F, Sperduti I, Maini CL. Natural history and clinical outcome of differentiated thyroid carcinoma: a retrospective analysis of 1503 patients treated at a single institution. Ann Oncol. 2009;20(10):1728-35.

17. Duntas L, Grab-Duntas BM. Risk and prognostic factors for differentiated thyroid cancer. Hell J Nucl Med. 2006;9(3):156-62.

18. Karam M, Gianoukakis A, Feustel PJ, Cheema A, Postal ES, Cooper JA. Influence of diagnostic and therapeutic doses on thyroid remnant ablation rates. Nucl Med Commun. 2003;24(5):489-95.

19. Ward LS, Assumpção LVM. Thyroid cancer: prognostic factors and treatment. Arq Bras Endo Metab. 2004;48(1):126-36.

20. Mazzaferri EL, Jhiang SM. Long-term impact of initial surgical and medical therapy on papillary and follicular thyroid cancer. Am J Med. 1994;97(5):418-28.

21. Steinmüller T, Klupp J, Rayes N, Ulrich F, Jonas S, Gräf KJ, et al. Prognostic factors in patients with differentiated thyroid carcinoma. Eur J Surg. 2000;166(1):29-33.

22. Mihailovic J, Stefanovic L, Malesevic M, Markoski B. The importance of age over radioiodine avidity as a prognostic factor in differentiated thyroid carcinoma with distant metastases. Thyroid 2009;19(3):227-32.

23. Zucchelli G, lervasi A, Ferdeghini M, lervasi G. Serum thyroglobulin measurement in thefollow-up of patients treated for differentiated thyroid cancer. Q J Nucl Med Mol Imaging. 2009;53(5):482-9. 